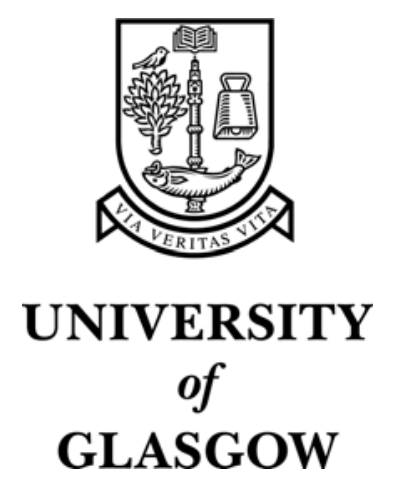

Ternent, G. and Asenov, A. and Thayne, I. G. and MacIntyre, D. S. and Thom, S. and Wilkinson, C. D. W. and Parker, E. H. C. and Gundlach, A. M. (1999) SiGe p-channel MOSFETs with tungsten gate. Electronics Letters 35(5):pp. 430-431.

http://eprints.gla.ac.uk/2970/ 


\section{SiGe $p$-channel MOSFETs with tungsten gate}

G. Ternent, A. Asenov, I.G. Thayne, D.S. MacIntyre, S. Thoms, C.D.W. Wilkinson, E.H.C. Parker and A.M. Gundlach

A self-aligned SiGe $p$-channel MOSFET tungsten gate process with $0.1 \mu \mathrm{m}$ resolution is demonstrated. Interface charge densities of MOS capacitors realised with the low pressure sputtered tungsten process are comparable with thermally evaporated aluminium gate technologies $\left(5 \times 10^{10} \mathrm{~cm}^{-2}\right.$ and $2 \times 10^{11} \mathrm{~cm}^{2}$ for $\mathrm{W}$ and $\mathrm{Al}$, respectively). Initial results from $1 \mu \mathrm{m}$ gate length $\mathrm{SiGe}$ $p$-channel MOSFETs using the tungsten-based process show devices with a transconductance of $33 \mathrm{mS} / \mathrm{mm}$ and effective channel mobility of $190 \mathrm{~cm}^{2} / \mathrm{Vs}$.

Introduction: Recently there has been significant improvement in the performance of SiGe $p$-channel MOSFETs, strained Si $n$-channel MODFETs and scaled bulk Si devices [ $1-3]$. The motivation for these enhancements is driven by CMOS shrinkage requirements, but also by the goal of realising microwave and millimetre wave Si-based transceiver circuitry compatible with a standard CMOS process flow.

One of the outstanding technological issues limiting the performance of $0.1 \mu \mathrm{m}$ gate length Si-based MOSFETs for both CMOS and RF applications is the high resistance of conventional poysilicon gate processes [4]. This has led to the development of complex silicide and salicide gate stack processes [5] as well as the demonstration of metal gate CMOS devices [6].

In this Letter a self-aligned SiGe $p$-channel MOSFET tungsten gate technology with $0.1 \mu \mathrm{m}$ resolution is described, together with the first results on $1 \mu \mathrm{m}$ gate length SiGe $p$-channel MOSFETs realised with the process.
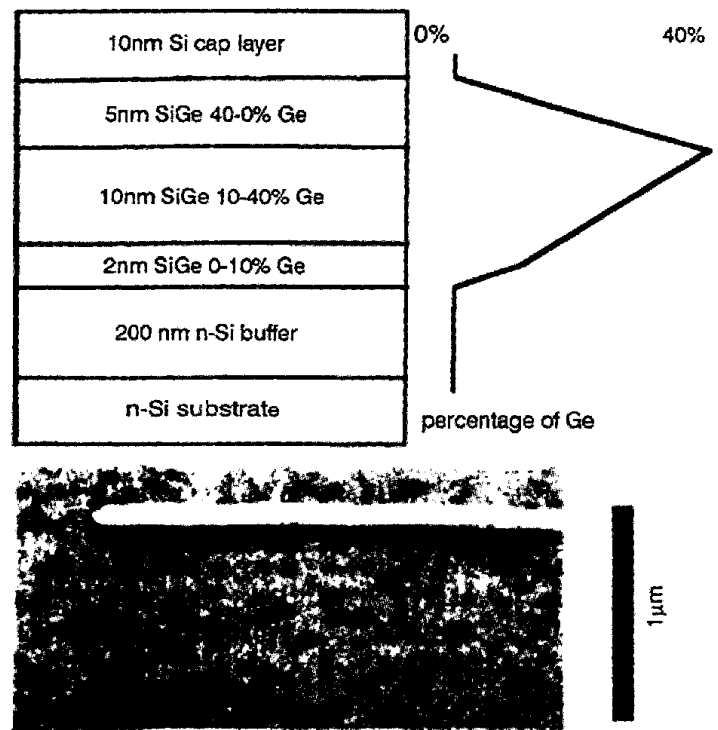

Fig. 1 Layer structure showing percentage of Ge concentration, and $S E M$ of $100 \mathrm{~nm} W$ gate

a Layer structure

$b$ SEM

Fabrication: The layer structure on which devices are fabricated was grown by MBE and is shown in Fig. $1 a$. Using both step and linear grading, a maximum Ge concentration of $40 \%$ in the channel was achieved. The $200 \mathrm{~nm}$ buffer layer, doped at $5 \times 10^{17} \mathrm{~cm}^{-3}$ $n$-type with $\mathrm{Sb}$, is grown on an $n$-type $\mathrm{Si}$ substrate doped at $5 \times$ $10^{16} \mathrm{~cm}^{-3}$. The channel comprises three layers: a $2 \mathrm{~nm}$ SiGe layer graded from 0 to $10 \%$ Ge followed by a $10 \mathrm{~nm}$ SiGe layer graded from 10 to $40 \% \mathrm{Ge}$, then a $5 \mathrm{~nm}$ SiGe layer graded from 40 to $0 \%$ Ge. Approximately $5 \mathrm{~nm}$ of the $10 \mathrm{~nm} \mathrm{Si}$ cap layer is consumed during the cleaning and oxidation processes. All layers above the buffer are nominally undoped at a background level of $10^{15} \mathrm{~cm}^{-3} \mathrm{n}-$ type.

The device process flow begins with the growth of a $6 \mathrm{~nm}$ gate oxide using a $200 \mathrm{~min}$ dry thermal oxidation performed at $750^{\circ} \mathrm{C}$ to prevent any out-diffusion of $\mathrm{Ge}$ during the oxide growth. A further $30 \mathrm{~min} 750^{\circ} \mathrm{C}$ anneal in an argon atmosphere results in a device quality oxide layer. Next, the $100 \mathrm{~nm}$ thick tungsten gate is deposited by RF sputtering at a pressure of 2 mtorr and power of $100 \mathrm{~W}$. To enable an assessment of the damage induced by the sputtered tungsten process to be made, $100 \mathrm{~nm}$ thick thermally evaporated aluminium gate MOS capacitors were also defined for comparison.

Tungsten gates with minimum feature sizes of $100 \mathrm{~nm}$ as shown in Fig. $1 b$, were fabricated using a Leica Microsystems Lithography LTD EBPG5 beamwriter and AZPN114 negative tone resist to define the geometry, followed by tungsten patterning with a $2 \mathrm{~min}, 100 \mathrm{~W} \mathrm{SF}_{6}$ reactive ion etch performed at $9 \mathrm{mtorr}$. In situ reflectometry was used during the $\mathrm{SF}_{6}$ etch to stop the gate metal etch on the thin $6 \mathrm{~nm} \mathrm{SiO}_{2}$ layer [7]. The self-aligned source and drain contacts were produced using a shallow $(<100 \mathrm{~nm}) \mathrm{BF}_{2}$ implant at an energy of $10 \mathrm{keV}$ and a dose of $10^{15} \mathrm{atom} / \mathrm{cm}^{2}$ activated by a $10 \mathrm{~s} 900^{\circ} \mathrm{C}$ anneal. Source and drain metallisation of $100 \mathrm{~nm}$ AlSi was followed by a $5 \mathrm{~min} 400^{\circ} \mathrm{C}$ anneal. Finally, the devices were shallow trench isolated with a $5 \mathrm{~min}, 100 \mathrm{~W} \mathrm{SF}_{6}$ reactive ion etch performed at $9 \mathrm{mtorr}$.

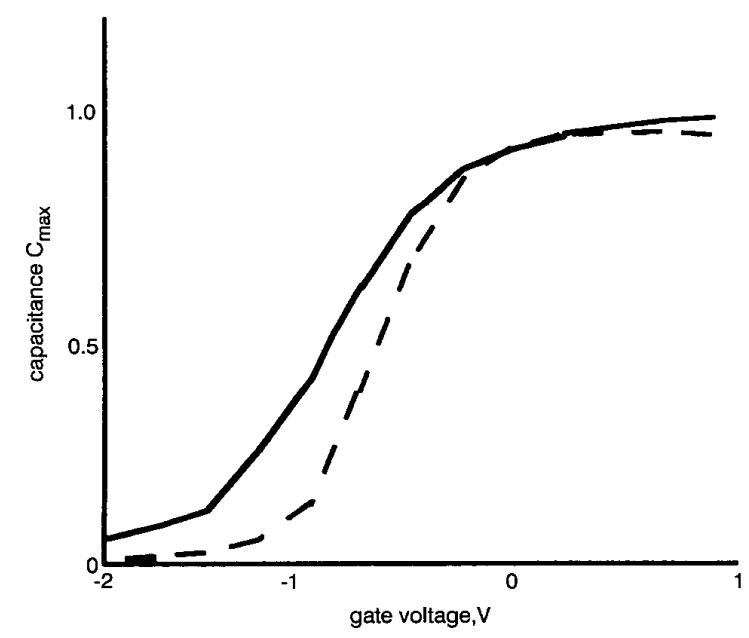

$110 / 2$

Fig. $2 \mathrm{CV}$ characteristics of $W$ and Al MOS capacitors (20nm thick oxide)

$\begin{aligned} \mathrm{Al}, Q_{\text {int }} & =2 \times 10^{11} \mathrm{~cm}^{-2} \\ ---\mathrm{W}, Q_{i u} & =5 \times 10^{10} \mathrm{~cm}^{-2}\end{aligned}$
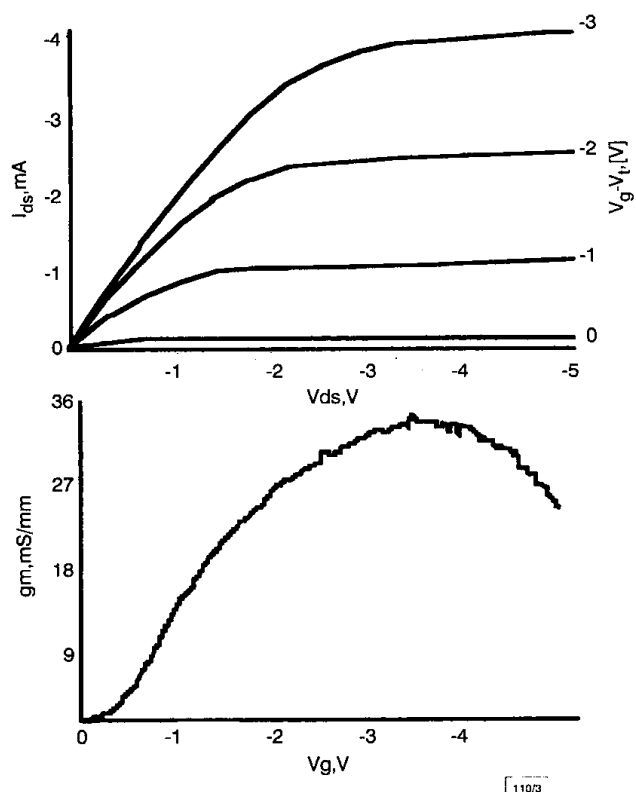

$[1,0 ; 3$

Fig. $3 \mathrm{I}-\mathrm{V}$ and $g_{m}$ characteristics of $1 \mu \mathrm{m} \times 100 \mu \mathrm{m}$ p-SiGe $W$ gate $M O S F E T$ 
Results: Fig. 2 shows the $\mathrm{CV}$ curve of $\mathrm{SiGe}-\mathrm{SiO}_{2}$ capacitors realised using both the sputtered tungsten and evaporated aluminium gate metallisations. The interface charge densities calculated from the flatband voltage shifts are $5 \times 10^{10} \mathrm{~cm}^{-2}$ and $2 \times 10^{11} \mathrm{~cm}^{-2}$ for W and $\mathrm{Al}$, respectively, showing that the sputtered tungsten gate process causes only a small amount of damage. In addition the larger work function of tungsten results in a lower flatband voltage and thus a reduced threshold voltage when compared with the aluminium gate capacitors.

Using both the van der Pauw and four probe TLM methods, the resistivity of the $100 \mathrm{~nm}$ thick sputtered tungsten gate metal film was determined to be $1.2 \Omega / \square$, a factor of 3 lower than similar geometry polysilicon and silicide gate structures [8]. The measured resistivity was independent of gate length down to $100 \mathrm{~nm}$.

Fig. 3 shows the $I_{d s}\left(V_{c k}, V_{g s}\right)$ and $g_{m}\left(V_{g s}\right)$ characteristics of a $1 \times$ $100 \mathrm{~mm}$ gate length $\mathrm{SiGe}$ MOSFET realised using the process described above. The maximum extrinsic transconductance is $33 \mathrm{mS} / \mathrm{mm}$. Estimating the channel hole concentration from the $\mathrm{C}(\mathrm{V})$ characteristic of the device and accounting for the channel access resistance of $500 \Omega$ measured with TLM structures, an effective channel mobility of $190 \mathrm{~cm}^{2} / \mathrm{Vs}$ was extracted from the channel conductance at low drain bias $\left(V_{d s}=-0.1 \mathrm{~V}\right)$.

Conclusion: We have demonstrated a self-aligned $\mathrm{SiGe} p$-channel MOSFET tungsten gate process with $0.1 \mu \mathrm{m}$ resolution. Interface charge densities of MOS capacitors realised with the low pressure sputtered tungsten process are comparable with thermally evaporated aluminium gate technologies $\left(5 \times 10^{10} \mathrm{~cm}^{-2}\right.$ and $2 \times 10^{11} \mathrm{~cm}^{-2}$ for $\mathrm{W}$ and $\mathrm{Al}$, respectively) indicating that this a low damage process. The use of a tungsten gate produces devices with gate resistances of $1.2 \Omega / \square$ independent of gate length down to $100 \mathrm{~nm}$, making this process an attractive candidate for the realisation of low gate resistance devices for RF applications.

Initial results from $1 \mu \mathrm{m}$ gate length $\mathrm{SiGe} p$-channel MOSFETs using the tungsten-based self-aligned gate process yielded a transconductance of $33 \mathrm{mS} / \mathrm{mm}$ and effective channel mobility of $190 \mathrm{~cm}^{2} / \mathrm{Vs}$

(c) IEE 1999

Electronics Letters Online No: 19990305

DOI: 10.1049/el:19990305

28 January 1999

G. Ternent, A. Asenov, I.G. Thayne, D.S. Macintyre, S. Thoms and C.D.W. Wilkinson (Department of Electronics and Electrical Engineering, The Rankine Building, University of Glasgow, Glasgow, G12 $8 Q Q$, United Kingdom)

E.H.C. Parker (Department of Physics, University of Warwick, Coventry, CV4 $7 A L$, United Kingdom)

A.M. Gundlach (Department of Electrical Engineering, University of Edinburgh, The Kings Buildings, Edinburgh, EH9 3JL, United Kingdom)

\section{References}

1 VERDONCKT-VANDEBROEK, S., CRABBE, E.L.F., MEYERSON, B.S., HARAME, D.L., RESTLE, P.J., STORK, J.M.C., and JOHNSON, J.B.: 'SiGechannel heterojunction p-MOSFETs', IEEE Trans., 1994, ED-41, pp. $90-99$

2 MAITI, C.K., BERA, L.K., and CHATTOPADHYAY, S.: 'Strained-Si heterostructure field effect transistors', Semicond. Sci. Technol. 1998, 13, (11), pp. 1225-1246

3 TAUR, Y., BUCHANAN, D.A., CHEN, W., FRANK, D.J., ISMAIL, K.E., LO, S. H., SAI-HALASZ, G.A., VISWANATHAN, R.G., WANN, H.-J.C., WIND, S.J., and WONG, H.-S.: 'CMOS scaling into the nanometer regime', Proc. IEEE, 1997, 85, (4), pp. 486-504

4 SHAHIDI, G.G., WARNOCK, J.D., COMFORT, J., FISCHER, S., MCFARLAND, P.A., ACOVIC, A., CHAPPELL, T.I., CHAPPELL, B.A NING, T.H., ANDERSON, C.J., DENNARD, R.H., SUN, J.Y.-C., POLCARI, M.R., and DAVARI, B.: "CMOS Scaling in the $0.1-\mu \mathrm{m}, 1 . \mathrm{X}$ Volt regime for high performance applications', IBM J. Res. Develop., 1995, 39, (1/2), pp. 229-242

5 RISHTON, S., MII, Y.J., KERN, D.P., TAUR, Y., LEE, K.E., LII, T., and JENKINS, K: 'High-performance sub-0.1 $\mu \mathrm{m}$ silicon $n$-metal oxide semiconductor transistors with composite metal polysilicon gates', J. Vac. Sci. Technol. B, 1993, 11, (6), pp. 2612-2614

6 BUCHANAN, D., MCFEELY, F., and YURKAS, J.: 'Fabrication of midgap metal gates compatible with ultrathin dielectrics', Appl. Phys. Lett., $1998,73,(12)$, pp. 1676-1678
7 HICKS, S.E., PARKES, W., WILKINSON, J.A.H., and WILKINSON, C.D.W.: 'Reflectance modeling for in situ dry etch monitoring of bulk $\mathrm{SiO}_{2}$ and III-V multilayer structures', J. Vac. Sci. Technol. B, 1994, 12, (6), pp. $3306-3310$

8 SHAHIDI, G.G., WARNOCK, J.D., COMFORT, J., FISCHER, S. McFARLAND, P.A., ACOVIC, A., CHAPPELL. T.I., CHAPPELL, B.A., NING, T.H., ANDERSON, C.J., DENNARD, R.H., SUN, J.Y.C. POLCARI, M.R., and DAVARI, B.: 'CMOS scaling in the $0.1 \mu \mathrm{m}, 1 . \mathrm{X}$ Volt regime for high performance applications', IBM J. Res. Develop., 1995, 39, (1/2), pp. 229-242

\section{Ultra-shallow junction technology by atomic layer doping from arsenic adsorbed layer}

Y.H. Song, J.C. Bae, M. Oonishi, T. Honda, H. Kurino and $\mathrm{M}$. Koyanagi

A novel S/D junction technology for realising sub- $0.1 \mu \mathrm{m}$ NMOSFETs is proposed. In this technology, S/D extensions are formed using arsenic (As) diffusion from an As adsorbed atomic layer on the silicon surface by high temperature RTA. This method provides an extremely shallow extension (below $20 \mathrm{~nm}$ ) with low sheet-resistance (below $2 \mathrm{k} \Omega / \square$ ), maintaining a low junction leakage. NMOSFETs fabricated using this technology show better suppression of the short channel effect compared to conventional FETs.

Introduction: In sub-0.1 $\mu \mathrm{m}$ NMOSFETs, an extremely shallow junction in a source and drain region is required to suppress a short channel effect (SCE). Recent shallow doping methods instead of low energy As implantation have mainly used phosphorus ion as a dopant [1]. Although $\mathrm{As}$ is the preferred N-type dopant in the shallow junction formation, another As doping method apart from ion implantation has not been presented until now.

In this Letter, we investigate the As diffusion from an As adsorbed atomic layer on the silicon surface, and propose process conditions to achieve ultra-shallow junction with low resistance and low junction leakage. Finally, the device characteristics of sub $0.1 \mu \mathrm{m}$ NMOSFETs fabricated by this method are evaluated.

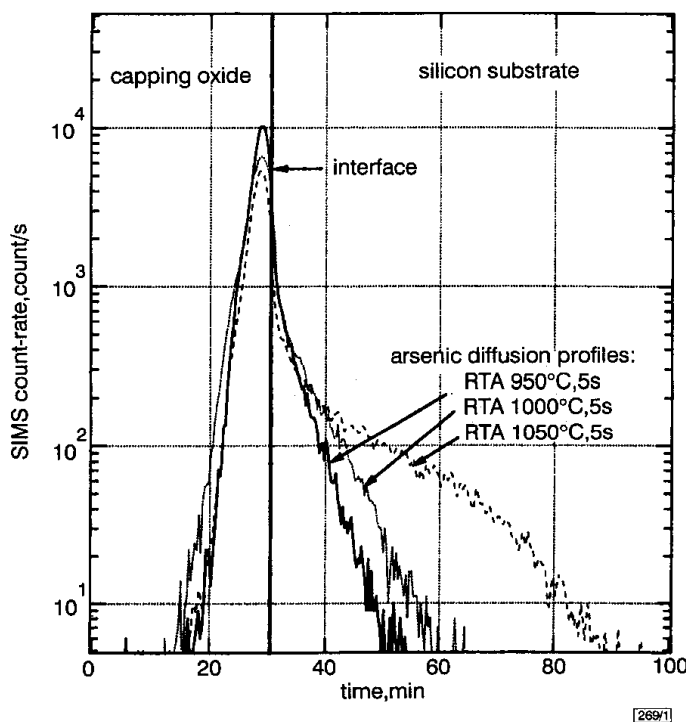

Fig. 1 Typical SIMS profiles under different RTA conditions of As atomic layers formed by $\mathrm{AsH}_{3}$ injection at $550^{\circ} \mathrm{C}$ for $30 \mathrm{~min}$

Shallow junction formation: The As layer doping consists of three essential steps. First, $\mathrm{AsH}_{3}$ is supplied to the silicon surface for the As layer formation. Secondly, non-doped silicon glass (NSG) film, used as a capping film, is deposited on the As adsorbed layer by using the APCVD method. Thirdly, rapid thermal annealing (RTA) is carried out. The maximum As coverage ( 0.95 monolayer) on the silicon surface was obtained at $\mathrm{AsH}_{3}$ reaction temperature 